\title{
RELATIONSHIP BETWEEN OPERATIONAL CHARACTERISTICS OF SMALL NON-COMMUNITY DRINKING WATER SYSTEMS AND ADVERSE WATER QUALITY INCIDENTS IN SOUTHERN ONTARIO, CANADA
}

\author{
SeKercioglu, M. F. ${ }^{1 *}-$ White, J. ${ }^{2}-$ Shrubsole, D. ${ }^{3}-$ BAXTER, J. ${ }^{4}$ \\ ${ }^{1}$ Department of Geography, Room 2322, Social Science Centre, Western University \\ 1151 Richmond Street, London, Ontario, Canada, N6A $3 K 7$ \\ (phone: +1-226-700-3422) \\ ${ }^{2}$ Department of Sociology, Room 5412, Social Science Centre, Western University \\ 1151 Richmond Street, London, Ontario, Canada, N6A 3 K7 \\ (phone: +1-519-661-2111 ext. 85230) \\ ${ }^{3}$ Department of Geography, Room 9438, Social Science Centre, Western University \\ 1151 Richmond Street, London, Ontario, Canada, N6A 3 K7 \\ (phone: +1-519661-2111 ext. 88099) \\ ${ }^{4}$ Department of Geography, Room 1407, Social Science Centre, Western University \\ 1151 Richmond Street, London, Ontario, Canada, N6A $3 K 7$ \\ (phone: +1-519-661-2111 ext. 81241) \\ *Corresponding author \\ e-mail: msekerci@uwo.ca; phone: +12-2-670-03422 \\ (Received $17^{\text {th }}$ Sep 2017; accepted $11^{\text {th }}$ Jan 2018)
}

\begin{abstract}
Ensuring that water sources are safe by protecting them from disease causing organisms is integral for the continued health of people as drinking contaminated water leads to waterborne diseases which can be life-threatening. The purpose of this study is to examine small non-community drinking water systems' (SDWSs) operational characteristics and their relationships with adverse water quality incidents (AWQIs) which is defined as presence of total coliforms and/or Escherichia coli. We explored the relationship between operational characteristics of SDWSs and the occurrence of adverse water quality outcomes using de-identified data provided by Wellington-Dufferin-Guelph Public Health, Ontario. We examined the associations between water system operational characteristics and the adverse water quality outcome using logistic regression models. The analyses results indicated that operator training was associated with a lower risk for AWQI. None of the other predictors were significantly associated with AWQI: treatment method, water source, operating period, or sampling frequency. Our research concluded that the presence of operator training, an upstream behavioural determinant, is related to the incidence of AWQIs in SDWSs in Ontario, Canada. The high percentage of SDWSs with no treatment and lack of interest in testing for chemicals are potential areas of concern for ensuring the provision of safe drinking water from these systems.
\end{abstract}

Keywords: waterborne diseases, small drinking water systems, safety, total coliforms, Escherichia coli, operator training

\section{Introduction}

Behavioral influences on multi-user, non-household, public water systems have been understudied in the developed world. The drinking water system, which includes water source, treatment, distribution, and discharge requires the good use of 
technology and well-trained people to operate it. Several disease-causing organisms and substances are transmitted by water. Ensuring that water sources are of good quality and water treatment is done effectively are fundamental to protect the public's health (Coleman et al., 2013). In simple terms, drinking water is considered safe when it does not contain pathogens or unsafe concentrations of toxic chemicals or radioactive substances (MOE, 2006). Although approximately 15\% of Canadians use Small Non-Community Drinking Water Systems (SDWSs), more than 50\% of the waterborne outbreaks in Canada are associated with these systems (Pons et al., 2015). This study aims to examine the SDWS operational characteristics and their relationships with Adverse Water Quality Incidents (AWQIs).

There are several environmental determinants of water source contamination. Water quality degrades during extreme weather events such as drought and heavy rainfall, which consequently increases the risk for adverse health outcomes in affected communities (Delpla et al., 2009). According to O'Dwyer et al. (2014), aquifer type and rainfall amount impact the vulnerability of groundwater sources. Collins et al. (2005) and Park et al. (2014) also identify a correlation between the increased rainfall amount and the presence of Escherichia coli (Migula, 1895) in water sources (surface and/or ground water). Another significant cause of ground water contamination with total coliform and E. coli is industrial activities such as mining operations (Armah, 2014) and livestock or non-point sources. Total coliform bacteria include several soil bacteria and are not likely to cause illness, but their presence indicates that the water system may be prone to contamination, whilst E. coli is commonly found in the intestines of mammals, including humans (Armah, 2014). The genera that belongs to coliforms include several organisms including Citrobacter, Enterobacter, Klebsiella (Harwood et al., 1999).

Rizak et al. (2003) note that water source contamination should be addressed using a holistic approach. In addition to environmental effects, social and behavioral characteristics play significant roles in water contamination that cause waterborne human disease outbreaks (Heymann, 2005). Social and behavioral factors underpinned by complacency contributed to the Walkerton tragedy in Ontario, Canada in May 2000 when Escherichia coli 0157:H7 entered the water system and led to the deaths of seven people and made over 2300 people ill (Huck et al., 2003). Hrudey and Hrudey (2007) analyzed the cause of 74 recent waterborne outbreaks across the world and identified the major contributing factors to these incidents as insufficient source water knowledge, lack of disinfection, and operational deficiencies, which suggests that adequate operator training could have potentially prevented these outbreaks. Ercumen et al. (2014) examine the correlation between water distribution systems and gastrointestinal illnesses and conclude that operational deficiencies result in significant increase of gastrointestinal illnesses among users. According to Craun et al. (2001) distribution system issues not addressed by the operators are the leading cause of waterborne outbreaks. In other words, 'the environment' or water source is not the major contributing factor, it is human and technological deficiencies. Pons et al. (2015) notes that etiology was not identified in more than half of the reported waterborne outbreaks in Canada and the United States between 1970 and 2014 whilst, Giardia intestinalis was the most commonly identified pathogen followed by Norovirus and Campylobacter jejuni respectively. Enhanced reporting and identification of waterborne outbreaks would contribute to the explanation of the region's general characteristics and initiate strategies to prevent future occurrences. 
Climate change will impact the operations of SDWSs significantly with reduced water quality and availability (Grover, 2012). Frequent extreme weather events will result in increased number of waterborne outbreaks (Thomas et al., 2006; Cann et al., 2013). The operators and users of SDWSs will be unjustly affected as these systems have lower adaptive capacity and high vulnerability than Community Drinking Water Systems (CDWSs) (Cann et al., 2013). Social dimensions of SDWS operation should be examined to address current and emerging issues for the provision of safe drinking water.

The operator training in SDWSs can be considered an upstream behavioural determinant (Gehlert et al., 2008; Williams et al., 2008) within the context of environmental and societal factors. Dreibelbis et al. (2013) argue that behaviour change underpins enhanced water safety practices at individual, community and structural levels.

Most of the research and regulatory attention has been placed on industrial and municipal water systems because of their size and potential health risks in the event of inadequate treatment. SDWSs are defined as systems that make drinking water available to the public and are not connected to a CDWS (MOHLTC, 2015). SDWSs potentially fall through the regulatory cracks in Ontario and elsewhere as either they are not regulated or their regulatory requirements are considerably less stringent. Relative to urban water users, these factors could contribute to a greater potential risk faced by users of SDWSs. Furthermore, the number of people experiencing waterborne illnesses from SDWSs is predicted to be significantly higher than the documented cases since there is no national waterborne illness surveillance system (Schuster et al., 2005; Wilson et al., 2009).

Therefore, there is a substantial need to better understand their weaknesses and strengths. With many of them facing significant challenges for the provision of safe drinking water, it is estimated that $20 \%$ of Ontarians use over 9000 SDWSs across the province (Pons et al., 2014; Pons et al., 2015). If we consider transient populations such as travelers, the number of SDWSs users is considerably higher than the initial estimates.

Pons et al. (2015) reviewed the waterborne disease outbreaks in SDWSs in the United States and Canada between 1970 and 2014, and concluded that untreated and inadequately treated water systems have been the leading cause of these outbreaks. Less is understood about the predictors of this inadequacy of treatment. Our study looks at a wider set of factors, so-called upstream behavioral determinants, that may be related to AWQIs. We seek to fill a knowledge gap concerning the relationship of SDWS operational characteristics and the provision of safe drinking water. The purpose of this study is to examine the SDWS operational characteristics and their relationships with AWQIs.

AWQIs are documented when a water sample test result does not meet the regulatory standards indicated for that test or the water system may not be able to supply safe drinking water (MOHLTC, 2009). Although the Ministry of Health and Long-Term Care (MOHLTC) identifies 11 conditions for an AWQI, the detection of total coliforms and/or $E$. coli constitutes the significant majority of these incidents (MOHLTC, 2009). Locas et al. (2008) examine the ground water quality in three Canadian provinces and conclude that sampling for total coliforms and $E$. coli is the best approach to assessing the bacteriological quality of drinking water. 
In Ontario, the detection of total coliforms or E. coli at any level in water sample constitutes an AWQI.

SDWSs are mandated by the MOHLTC to meet similar water safety standards with larger municipal CDWSs. The regulatory oversight of SDWSs was transferred from the Ministry of the Environment (MOE) to local health units under the MOHLTC in 2008. The Health Protection and Promotion Act (HPPA) regulates SDWSs, while the Safe Drinking Water Act provides legal oversight for CDWSs.

Five categories of SDWSs are: (1) Large municipal non-residential drinking water systems such as recreational facilities, (2) Small municipal non-residential drinking water systems, community centres and libraries, (3) Non-municipal seasonal residential drinking water systems such as privately owned cottages on communal system, (4) Large non-municipal non-residential drinking water systems such as motels, and (5) Small non-municipal non-residential drinking water systems such as restaurants and churches (MOHLTC, 2015). Ontario Regulation 319 (Small Drinking Water Systems) established under the HPPA regulates SDWSs making the owners of these systems legally responsible for complying with the requirements (MOHLTC, 2015).

There are 36 health units in Ontario, and 29 of these health units are located in Southern Ontario. The study region is the health unit of Wellington-Dufferin-Guelph Public Health (WDGPH) which includes Wellington and Dufferin Counties and the City of Guelph. This region, centrally located in Southern Ontario, has 98\% rural, and 2\% urban area with 229 SDWSs (WDGPH, 2016). We examined the operational characteristics of the 229 systems in this region with respect to experiencing AWQIs defined as an above guideline, positive test for total coliform and/or E. coli. The incidence of water-borne illness within the WDGPH jurisdiction has not been studied.

The objective of our study was to explore the relationship between characteristics of the water systems and the presence of the adverse outcome with total coliforms and/or E. coli between the years 2010 and 2015. We hypothesized that the presence or absence of AWQI can be predicted by whether the SDWS operator had received formal operator training or not after adjusting for water source (ground water, surface water or other), treatment method (UV, chlorination, combination of the two, or none), operating period (seasonal, year round) and sampling frequency.

\section{Methods}

\section{Data}

The data used for this study is a mixture of the outcome variable (presence of AWQIs with total coliforms and/or E. coli between 2010 and 2015), behavioral (operator training) and non-behavioral predictors (the location of the water system, water source, treatment method of the water system, operating period and sampling frequency) with 229 data points. As a result, the de-identified data employed in this study included information on characteristics of the water systems and operations as well as the presence of AWQIs with total coliforms and/or E. coli. Public Health Inspectors from WDGPH collected the data between January 2010 and December 2015. The information included the name, location and contact information of the water system, any positive total coliforms and/or E. coli water test results (AWQIs) between 2010 and 2015; water source (ground water or surface water); treatment method (Ultraviolet [UV], Chlorinator, UV and Chlorinator, or no treatment); operation period (seasonal or year round operation); operator training as present or absent (whether the 
SDWS operator had received formal operator training or not); and sampling frequency per calendar year (number of samples in a calendar year) from 229 SDWSs in the region. Figure 1 depicts the AWQIs on the dot distribution map in Wellington-DufferinGuelph region.

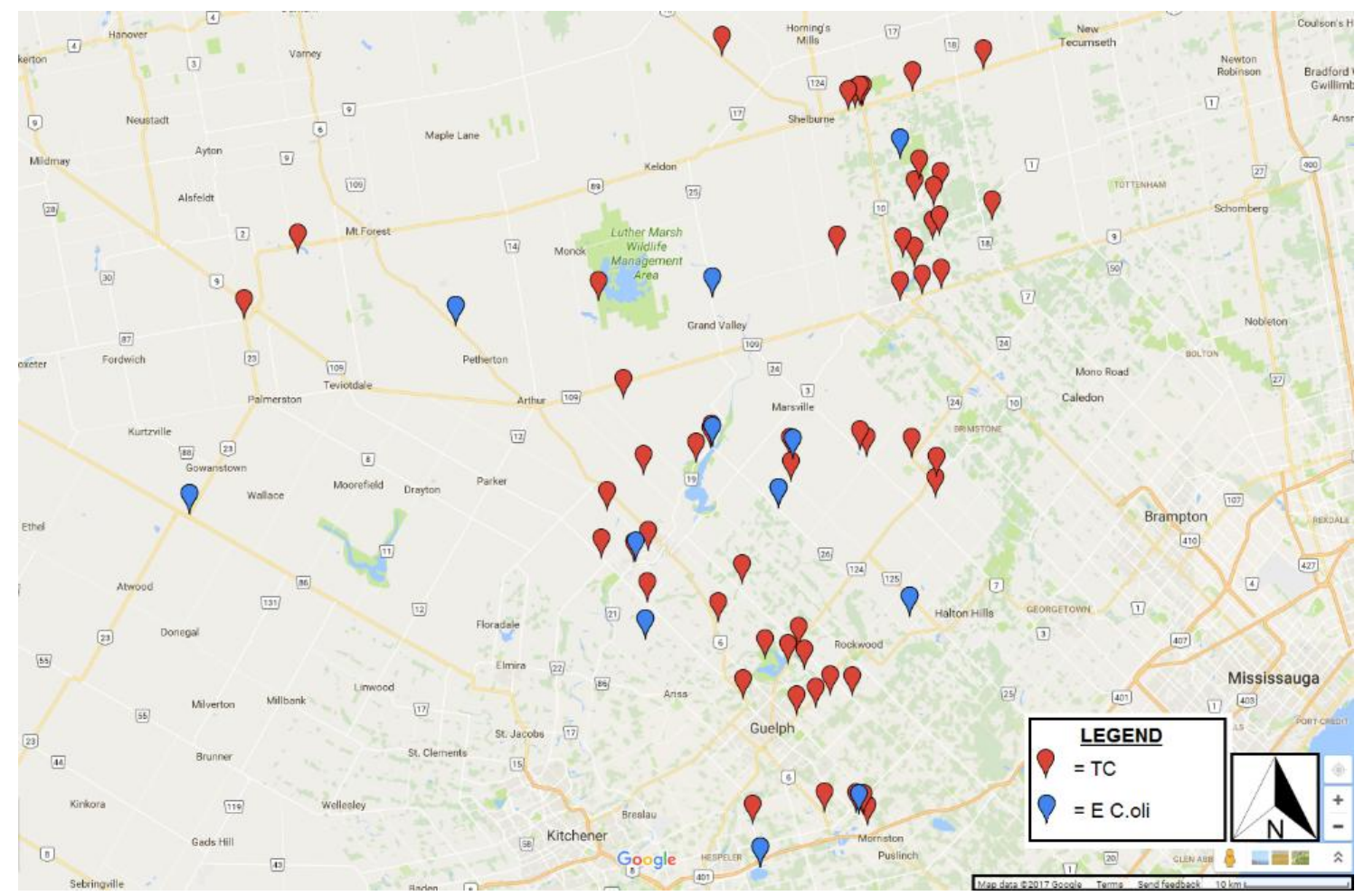

Figure 1. Map of AWQIs in Wellington-Dufferin-Guelph Region

\section{Analysis Plan}

The overall analysis strategy compared those with and without AWQIs. We planned to detect important patterns in all individual variables as well as the relationship between predictors and AWQI in both bivariate and more rigorous regression analyses. We started with descriptive statistics and provided a mean and standard deviation for our only discrete numerical variable (count data) which was sampling frequency. Frequencies and percentages were provided for categorical variables: water source (ground water or surface water, or other), treatment method (UV, chlorination, UV and chlorination, or none), operator training (present or absent) and operating period (seasonal or year around).

Two-sample t tests were used to compare mean differences between the groups (in those with and without an adverse water quality incident outcome) for sampling frequency with a student t-test. The Pearson chi-square test was employed to compare the distribution of categorical variables (water treatment, operating period, and operator training) in those with and without an AWQI. If the Pearson chi-square test assumption was violated (at least $80 \%$ of the expected counts are equal or greater than 5), we employed the Fisher's exact test as a substitute for the Pearson chi-square test when the expected counts were less. 
We tested pair-wise correlations between predictor variables using the Pearson correlation coefficient (r). We planned to remove the variable with lesser importance if $r$ was greater than 0.80 for 2 predictors. The linear regression model was used to generate collinearity statistics. Tolerance and variance inflation factor (VIF) were used to test the assumption. Values less than 10 for VIF, and more than 0.1 for tolerance were considered violations. All the values were below the limits for $r$ and VIF.

We also examined the associations between our outcome variable (AWQI) and all of the predictors (water source, treatment method, operating period, operator training and sampling frequency) using the logistic regression models in our inferential statistical analysis. We dichotomized the outcome into positive and negative adverse event which was defined by the MOHLTC (2009) guideline. Our logistic regression models explored the relationship between characteristics of the water systems (i.e. operator training, operating period, treatment, water source and sampling frequency) and the presence of the adverse outcome with total coliforms and/or E. coli in the past six years. The hypothesis of "the presence or absence of AWQI can be predicted by whether the SDWS operator had received formal operator training or not after adjusting for water source (ground water, surface water or other), treatment method (UV, chlorination, combination of the two, or none), operating period (seasonal, year round) and sampling frequency" was tested in the study sample. We reported odds ratios with $95 \%$ confidence intervals (CI).

Two-sided tests were employed with a significance level of 0.05 in our final model. All data analyses were performed using Stata (StataCorp., 2013). We also visually examined the map to verify the existence of clustering in data points.

\section{Results}

This study included 229 SDWSs from WDGPH. Two of the systems were eliminated from the data due to missing data (the sampling frequency was missing) and 18 SDWSs were posted ${ }^{1}$. As a result, we included a total of 209 water systems in our final analysis. The WDGPH data showed only two systems tested for chemical parameters.

Overall, a total of 165 water systems $(79 \%)$ did not have operator training whereas $44(21 \%)$ had operator training. Table 1 shows the characteristics of water systems divided by the presence of AWQIs. The group which had AWQIs had lower frequency of operator training as compared to the group without an AWQI ( $\mathrm{P}=0.02$, Table 1). We also examined the associations between operating period and AWQIs using the Pearson Chi-square test. The frequency was not significantly different between the groups (P: 0.71). Likewise, the associations between presence of treatment, water source and sampling frequency with AWQIs were not statistically significant $(\mathrm{P}=0.47, \mathrm{P}=0.32$, $\mathrm{P}=0.48$ ) (Table 1).

The distribution of water systems by treatment is depicted in Figure 2. A total of 59 $(27 \%)$ water systems did not use any treatment systems while $128(61 \%)$ employed UV to treat water. Sampling frequency ranged from 0 to 26 (Figure 2). The significant majority of the water systems $(n=207,99 \%)$ had ground water source while only two water systems had surface water.

\footnotetext{
${ }^{1}$ When a Small Drinking Water System is posted, the system owner is required to post signage regarding the public's access/consumption of water and the system is considered exempt from the operational requirements such as sampling, treatment and operator training (MOHLTC, 2015).
} 


$$
-783-
$$

Table 1. Characteristics of water systems divided by the presence of $A W Q I$

\begin{tabular}{|c|c|c|c|}
\hline Variables & $\begin{array}{c}\text { AWQI } \\
(n=68,33 \%)\end{array}$ & $\begin{array}{c}\text { No AWQI } \\
(n=141,67 \%)\end{array}$ & $P$ value \\
\hline $\begin{array}{ll}\text { Sampling } & \text { frequency; } \\
\text { mean (SD) } & \end{array}$ & $4.32(3.3)$ & $3.97(3.3)$ & 0.48 \\
\hline $\begin{array}{l}\text { Presence of treatment } \\
\text { Any treatment; } \mathrm{n}(\%) \\
\text { No treatment; } \mathrm{n}(\%)\end{array}$ & $\begin{array}{l}51(75 \%) \\
17(25 \%)\end{array}$ & $\begin{array}{l}99(70 \%) \\
42(30 \%)\end{array}$ & 0.47 \\
\hline $\begin{array}{l}\text { Treatment method } \\
\text { No treatment; } \mathrm{n}(\%) \\
\text { Chlorinated; } \mathrm{n}(\%) \\
\text { UV; } \mathrm{n}(\%) \\
\text { UV and chlorinated; n } \\
(\%)\end{array}$ & $\begin{aligned} 17 & (25 \%) \\
2 & (2 \%) \\
47 & (69 \%) \\
2 & (2 \%)\end{aligned}$ & $\begin{array}{c}42(29 \%) \\
10(7 \%) \\
80(56 \%) \\
9(6 \%)\end{array}$ & 0.26 \\
\hline $\begin{array}{l}\text { Operating period } \\
\text { Seasonal; } \mathrm{n}(\%) \\
\text { Year around; } \mathrm{n}(\%)\end{array}$ & $\begin{array}{l}18 \\
50\end{array}$ & $\begin{array}{c}34 \\
107\end{array}$ & 0.71 \\
\hline $\begin{array}{l}\text { Operator training } \\
\text { Positive; } \mathrm{n}(\%) \\
\text { Negative; } \mathrm{n}(\%)\end{array}$ & $\begin{array}{l}8(11 \%) \\
60(88 \%)\end{array}$ & $\begin{array}{l}36(25 \%) \\
105(74 \%)\end{array}$ & 0.02 \\
\hline $\begin{array}{l}\text { Water source } \\
\text { Ground water; n (\%) } \\
\text { Surface water; n (\%) }\end{array}$ & $\begin{array}{c}68(100 \%) \\
0(0 \%)\end{array}$ & $\begin{array}{c}139(98 \%) \\
2(2 \%)\end{array}$ & 0.32 \\
\hline
\end{tabular}

Note: Significant values are in bold with significance level of 0.05; AWQI: Adverse Water Quality Incident; SD: standard deviation

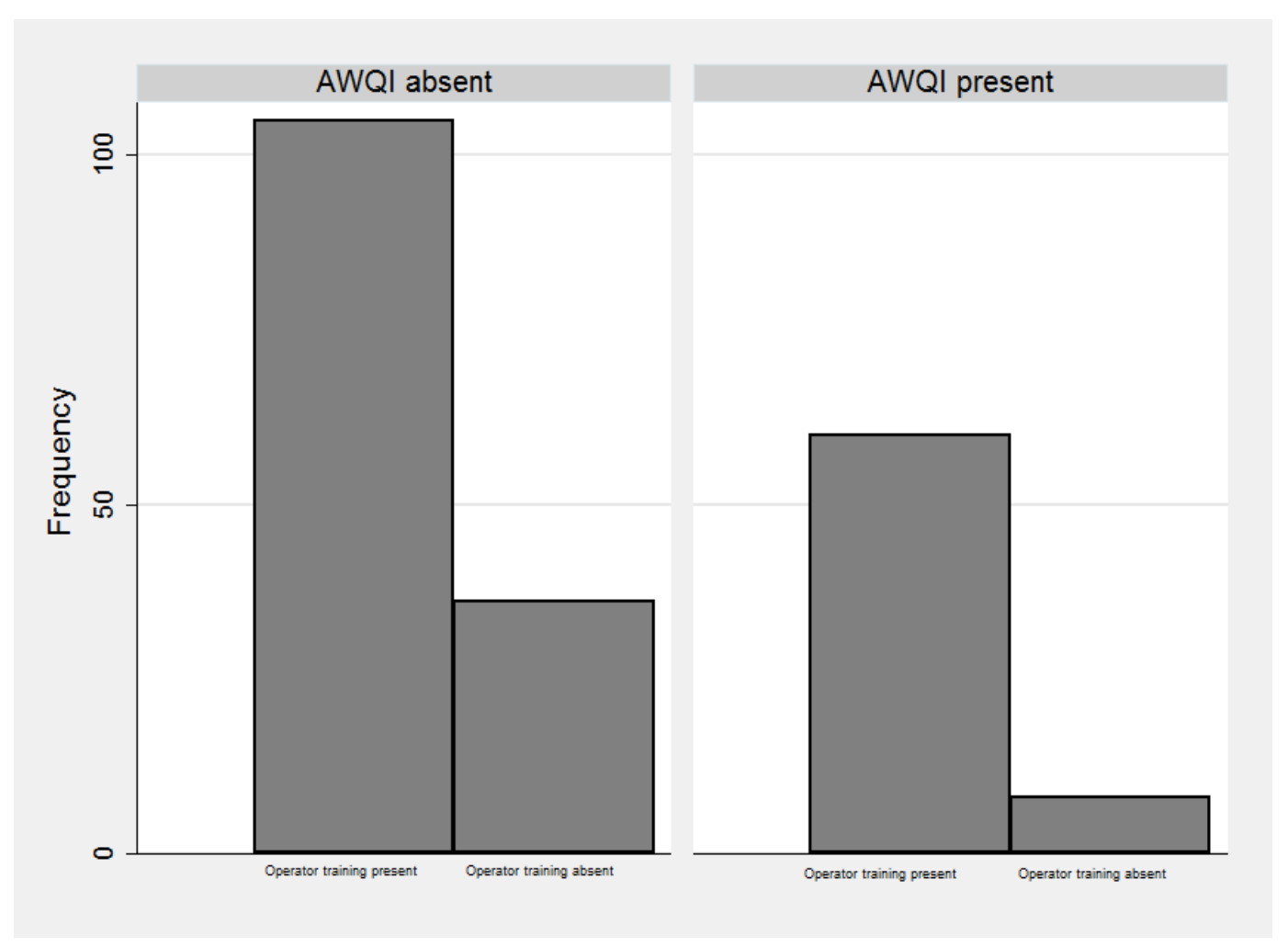

Figure 2. The Distribution of Water System by Operator training and adverse water quality incident 
To conclude, the results of the multivariate analyses indicated that operator training was associated with a lower risk for AWQI $(\mathrm{OR}=0.38,95 \% \mathrm{CI}=0.16$ to $0.89, \mathrm{P}=0.02)$ (Table 2). The treatment method, operating period and sampling frequency did not indicate statistically significant results (Table 2).

Table 2. Summary of our logistic models for AWQIs

\begin{tabular}{c|c|}
\hline Variable & $\begin{array}{c}\text { Effect estimate } \\
\text { OR }(\mathbf{9 5 \%} \mathbf{C I}) ; \mathbf{p}\end{array}$ \\
\hline Seasonality & $1.13(0.58$ to 2.19$) ; 0.37$ \\
Sampling frequency & $1.02(0.94$ to 1.11$) ; 0.49$ \\
Treatment & $1.27(0.65$ to 2.45$) ; 0.72$ \\
Operator training & $0.38(0.16$ to 0.89$) ; 0.02$ \\
Treatment (3 categories) & $1.12(0.82$ to 1.52$) ; 0.73$ \\
\hline
\end{tabular}

CI: confidence interval; OR: odds ratio

\section{Discussion}

The findings support the idea that upstream behavioral determinants, specifically operator training, plays an integral role in the provision of safe drinking water in SDWSs. The summary of our findings are as follows: (1) the SDWSs with trained operators were significantly less likely to have an AWQI; (2) there was not a significant association between AWQIs and treatment method, operating period or sampling frequency. (3) the distribution of treatment methods was as follows: $61 \%$ of SDWSs used a UV treatment system $(n=127) ; 28 \%$ of SDWSs did not use any treatment $(n=59)$; $6 \%$ used chlorination $(\mathrm{n}=12)$; and $5 \%$ used a combination of chlorination and UV treatment system $(n=11)$; (4) $1 \%$ of the SDWSs conducted chemical tests $(n=2)$ while $99 \%$ of the SDWSs did not conduct chemical tests $(n=207)$.

The findings about the operator training suggest the presence of trained operators in SDWSs significantly associated with the possibility of experiencing AWQIs. Review of the causes of recent waterborne disease outbreaks shows that meeting the regulatory water quality parameters alone is not sufficient to safely operate a drinking water system (Rizak et al., 2013). It is also fundamental to note that the lack of a robust surveillance system results in underreporting of waterborne disease outbreaks in SDWSs (Schuster et al., 2005; Wilson et al., 2009) which consequently hinders the development of interventions to increase the safety net for these systems. Xie et al. (1999) argue that small water systems face challenges to meet the regulatory requirements and operator training is essential to increase these systems' capacity to meet the regulations. According to Murphy et al. (2015), both owners and operators should receive water system training so that they can have a better understanding of the challenges for the provision of safe drinking water. Upstream determinants are fundamental parts of the social environment where individual differences in expression of feelings, thoughts and activities are shaped (Gehlert et al., 2008). The focus on operator training can be a viable intervention to address upstream behavioral determinants. Preventing illnesses by establishing mechanisms to increase the percentage of operators properly trained in SDSWs, supports the efforts to reduce health disparities (Williams et al. 2008). 
The Walkerton outbreak was a stark reminder the importance of operator training for the provision of safe drinking water. One of the major findings of the Walkerton tragedy was the complacency of the trained water system operators (Huck et al., 2003) where corrective action procedures were not diligently carried out prior to the outbreak. The operator training should be coupled with a better understanding of the consequences of not adequately responding to AWQIs. The Multiple-Barrier Approach (MBA) is an integrative risk management approach to water safety from source to tap. Baird et al. (2013) (as cited in Canadian Council of Ministers of the Environment, 2004, 16) explains the MBA as "an integrated system of procedures, processes and tools that collectively prevent or reduce the contamination of drinking water from source to tap in order to reduce risks to public health" (p.122). Water system operator training and establishing safety measures from source to tap are fundamental steps for the provision of safe drinking water.

Parr (2005) examined the societal effects and government approach to operator training just before the Walkerton outbreak and argues that the lack of consistency in training was a contributing factor to the outbreak. Training opportunities supported by the regulatory agencies assist SDWS owners and operators to enhance their capabilities for building and applying knowledge, which in return results in safer operations of these systems.

Over a quarter of the SDWSs in the Wellington-Dufferin-Guelph region operate with no treatment, yet a SDWS with no treatment system might be prone to contamination from external sources. Pons et al. (2015) reported that having no treatment system is one of the leading causes of outbreaks in SDWSs. Edwards et al. (2012) examined the safe operation characteristics of small commercial water systems in British Columbia, Canada, and concluded that the lack of a treatment system and water source vulnerability are among factors causing adverse conditions in SDWSs. Schuster et al. (2005) also identified treatment system failure along with inadequate operational practices as leading causes of waterborne outbreaks. The source water protection planning in Ontario does not include SDWSs therefore there is no enhanced safety net for these systems. Health risks of consuming water from an unprotected source are considerably high compared to a protected water source (Davies and Mazumder, 2003). The effects of climate change in the region, which include frequent extreme weather events, might put stress on the safety of the water sources. Thomas et al. (2006) and Cann et al. (2013) identify a correlation between increased amount of rainfall and waterborne disease outbreaks in Canada. SDWSs may not have sufficient resources and capacity to eliminate the adverse effects of extreme weather events which puts the safety of drinking water at risk. Dow et al. (2007) investigate the perceptions of water system managers about climate change effects and identify water quality, financial impact and scarcity of supply as major concerns. Source water protection is an integral step to protect SDWSs from impacts of climate change. Furthermore, complimentary strategies for source water protection, such as shoreline stewardship and groundwater sales policies, may become increasingly important in ensuring the safety of SDWS and CDWS alike.

The findings concerning treatment method were expected given that all of the technologies used are well understood. UV was the most commonly used water treatment method among SDWSs. UV treatment has been in the market for over 30 years but has gained popularity in the past decade (Corfield, 2015). In addition to treating microbiological contaminants, UV systems are effective on chlorine resistant species such as Giardia parasite and are therefore considered a viable option to enhance 
water quality (Corfield, 2015). Although UV treatment does not affect water properties such as chemistry and taste, the regular maintenance of the system is fundamental to maintain a safe operation (McClean, 2008). The widespread use of UV treatment in SDWSs reminds how essential the training component is for the provision of safe drinking water.

The findings about a lack of chemical testing are concerning. Chemical testing is an integral step to investigate potential threats to the water source which can be naturally occurring or human-made. Our dataset showed that only 1\% of the SDWSs had conducted chemical tests to understand the chemical composition of their water sources. Chemical contaminants in drinking water might cause several illnesses with serious and long-term health effects (Barrett, 2014). A study examining chemicals in water from 6013 private wells over a 12 month-period concluded that over $25 \%$ of the wells exceeded the acceptable levels of chemical contaminants (Harrison et al., 2000). Davies and Mazumder (2003) discussed the negative effects of agricultural, industrial and domestic use of chemicals on water sources and advocated for the reduction of their use and environmentally friendly disposal practices to reduce chemical contamination. Our study recommends greater emphasis on monitoring the chemical composition of the source water to confirm drinking water meets the regulatory limits.

There were several limitations of our study that shouldn't however undermine our findings about training. That said; this study involved secondary analysis of the existing data set therefore the number of variables was limited by the existing database. A variable that would be useful to include in a model of AWQI was risk category. The definition of AWQI is narrow in that we defined as incidents with positive total coliforms and/or $E$. coli test result as our dataset did not have consistent information for other conditions that may be classified as an AWQI. That said; presence of total coliforms in water sources is considered as one of the best pathogen indicators (Locas et al., 2007).

Further research is needed to explore the determinants of adverse water quality events with total coliforms and/or E. coli as well as other AWQI events like treatment system failures, structural deficiencies, and exceeding chemical parameters. Examining other upstream behavioural determinants within the context of environmental and societal norms will provide a deeper understanding of the current challenges of SDWSs in the provision of safe drinking water. Exploration of the factors associated with the adverse events will require a prospective well-designed and well-conducted study with a larger dataset with a possibility of linking records from several databases to retrieve complete information about SDWSs.

\section{Conclusion}

In Ontario, there are 36 health units with over 9000 SDWSs in their respective jurisdictions. Our analysis using the data from 229 SDWSs located in the WellingtonDufferin-Guelph region provided critical insight for operation and safety of these systems.

Our research concluded that the presence of operator training, an upstream behavioural determinant, significantly reduces the incidence of AWQIs in SDWSs. The high percentage of SDWSs with no treatment, lack of interest in testing for chemical parameters, and source water protection are potential areas of concern to ensure the provision of safe drinking water from these systems. Future research should attempt to flesh out the risk awareness and perceptions of SDWS owners to understand the challenges to operate these systems. 


\section{REFERENCES}

[1] Armah, F. (2014): Relationship between coliform bacteria and water chemistry in groundwater within gold mining environments in Ghana. - Water Quality, Exposure and Health 5(4): 183-195.

[2] Baird, J. M., Summers, R., Plummer, R. (2013): Cisterns and safe drinking water in Canada. - Canadian Water Resources Journal 38(2): 121-134.

[3] Barret, J. (2014): Chemical Contaminants in Drinking Water: Where Do We Go from Here? - Environmental Health Perspectives 122 (3): A80.

[4] CCME. (2004): From Source to Tap: Guidance on the Multi-Barrier Approach to Safe Drinking Water. - CCME (Canadian Council of Ministers of the Environment). Available at: http://www.ccme.ca/assets/pdf/mba_guidance_doc_e.pdf.

[5] Cann, K. F., Thomas, D. R., Salmon, R. L., Wyn-Jones, A., Kay, D. (2013): Extreme water-related weather events and waterborne disease. - Epidemiology and Infection 141(4): 671-686.

[6] Coleman, B. L., Louie, M., Salvadori, M. I., McEwen, S. A., Neumann, N., Sibley, K., McGeer, A. J. (2013): Contamination of Canadian private drinking water sources with antimicrobial resistant Escherichia coli. - Water Research 47(9): 3026-3036.

[7] Collins, R., Elliott, S., Adams, R. (2005): Overland flow delivery of faecal bacteria to a headwater pastoral stream. - Journal of Applied Microbiology 99(1): 126-132.

[8] Corfield, R. (2015): The next step for water purification. -Filtration and Separation 52(6): $38-40$.

[9] Craun G. F., Calderon R. L (2001): Waterborne disease outbreaks caused by distribution system deficiencies. - Journal of American Water Works Association (93): 64-75.

[10] Davies, J., Mazumder, A. (2003): Health and environmental policy issues in Canada: The role of watershed management in sustaining clean drinking water quality at surface sources. - Journal of Environmental Management 68(3): 273-286.

[11] Delpla, I., Jung, A., Baures, E., Clement, M., Thomas, O. (2009): Impacts of climate change on surface water quality in relation to drinking water production. - Environment International 35(8): 1225-1233.

[12] Dow, K., O'Connor, R. E., Yarnal, B., Carbone, G. J., Jocoy, C. L. (2007): Why worry? Community water system managers' perceptions of climate vulnerability. - Global Environmental Change 17(2): 228-237.

[13] Dreibelbis, R., Winch, P. J., Leontsini, E., Hulland, K. R., Ram, P. K., Unicomb, L., Luby, S. P. (2013): The Integrated Behavioural Model for Water, Sanitation, and Hygiene: a systematic review of behavioural models and a framework for designing and evaluating behaviour change interventions in infrastructure-restricted settings. - BMC Public Health 13:1015.

[14] Edwards, J. E., Henderson, S. B., Struck, S., Kosatsky, T. (2012): Characteristics of small residential and commercial water systems that influence their likelihood of being on drinking water advisories in rural British Columbia, Canada: a cross-sectional study using administrative data. - Journal of Water and Health 10 (4): 629-649.

[15] Ercumen, A., Gruber, J. S., Colford,J. M. (2014): Water distribution system deficiencies and gastrointestinal illness: A systematic review and meta-analysis. - Environmental Health Perspectives 122(7): 651.

[16] Gehlert, S., Sohmer, D., Sacks, T., Mininger, C., McClintock, M., Olopade, O. (2008): Targeting health disparities: A model linking upstream determinants to downstream interventions. - Health Affairs 27(2): 339-49.

[17] Grover, V. I. (2012): Impact of Climate Change on Water and Health. - CRC Press, London.

[18] Harrison, W. N., Bradberry, S. M., Vale, J. A. (2000): Chemical contamination of private drinking water supplies in the west midlands, United Kingdom. - Clinical Toxicology 38(2): 137-144. 
[19] Harwood, V. J., Butler, J., Parrish, D., Wagner, V. (1999): Isolation of Fecal Coliform Bacteria from the Diamondback Terrapin (Malaclemys terrapin centrata). - Applied and Environmental Microbiology 65(2): 865-867.

[20] Heymann, D. (2005): Social, Behavioural and Environmental Factors and Their Impact on Infectious Disease Outbreaks. - Journal of Public Health Policy 26(1): 133-139.

[21] Huck, P. M., Gillham, R. W., Hrudey, E. J. (2003): A fatal waterborne disease epidemic in Walkerton, Ontario: Comparison with other waterborne outbreaks in the developed world. - Water Science and Technology 47(3):7-14.

[22] Hrudey, S., Hrudey, E. (2007): Published Case Studies of Waterborne Disease Outbreaks-Evidence of a Recurrent Threat. - Water Environment Research 79(3): 233245.

[23] Locas, A., Barthe, C., Barbeau, B., Carriere, A. P. (2007): Virus occurrence in municipal groundwater sources in Quebec, Canada. - Canadian Journal of Microbiology 53(6): 688694.

[24] Locas, A., Barthe, C., Margolin, A. B. (2008): Groundwater microbiological quality in Canadian drinking water municipal wells. - Canadian Journal of Microbiology 54(6): 472-478.

[25] McClean, J. (2008): Water disinfection enhanced with ultraviolet light. - Water \& Wastewater International (23):18-19.

[26] Migula, W. (1895): Bacteriaceae (Stäbchenbacterien). - In: Engler, A. (ed.) Die Natürlichen Pflanzenfamilien. Teil I, Abteilung Ia, 20-30, W. Engelmann, Leipzig.

[27] Ministry of the Environment (MOE). (2006): Technical Support Document for Ontario Drinking Water Standards, Objectives and Guidelines. - Available at: http://www.ontla.on.ca/library/repository/mon/14000/263450.pdf.

[28] Ministry of Health and Long-Term Care (MOHLTC). (2009): Response to Adverse Drinking Water Quality Incident. - Available at http://www.health.gov.on.ca/en/pro/programs/publichealth/oph_standards/docs/guidance/ guidance_adverse_drinking_water.pdf.

[29] Ministry of Health and Long-Term Care (MOHLTC). (2015): Small Drinking Water Systems. $\quad-\quad$ Available at: http://www.health.gov.on.ca/english/public/program/pubhealth/safewater/safewater_faq.h tml.

[30] Murphy, H. M., Corston-Pine, E., Post, Y., McBean, E. A. (2015): Insights and opportunities: Challenges of Canadian first nations drinking water operators. International Indigenous Policy Journal 6(3): 1-17.

[31] O'Dwyer, J., Dowling, A., Adley, C. C. (2014): Microbiological assessment of private groundwater-derived potable water supplies in the Mid-West Region of Ireland. - Journal of Water and Health 12(2): 310-317.

[32] Park, S., Navratil, S., Gregory, A., Bauer, A., Srinath, I., Szonyi, B., Nightingale, K., Anciso, J., Jun, M., Han, D., Lawhon, S., Ivanek, R. (2014): Farm Management, Environment, and Weather Factors Jointly Affect the Probability of Spinach Contamination by Generic Escherichia coli at the Preharvest Stage. - Applied Environmental Microbiology 80(8): 2504-2515.

[33] Parr, J. (2005): Local water diversely known: Walkerton, Ontario 2000 and after. Environment and Planning D, Society and Space 23(2): 251-271.

[34] Pons, W., McEwen, S. A., Pintar, K., Jones-Bitton, A., Young, I., Papadopoulos, A. (2014): Experience, training and confidence among small, non-community drinking water system operators in Ontario, Canada. - Journal of Water and Health 12(4): 782-790.

[35] Pons, W., Young, I., Truong, J., Jones-Bitton, A., McEwen, S., Pintar, K., Papadopoulos, A. (2015): A systematic review of waterborne disease outbreaks associated with small non-community drinking water systems in Canada and the United States: E0141646. PLoS One 10(10): e0141646. 
[36] Rizak, S., Cunliffe, D., Sinclair, M., Vulcano, R., Howard, J., Hrudey, S., Callan, P. (2003): Drinking water quality management: a holistic approach. - Water Science and Technology 47(9): 31-36.

[37] Schuster, C. J., Ellis, A. G., Robertson, W. J., Charron, D. F., Aramini, J. J., Marshall, B. J., Medeiros, D. T. (2005): Infectious disease outbreaks related to drinking water in Canada, 1974-2001. - Canadian Journal of Public Health 96(4): 254-258.

[38] Thomas, K. M., Charron, D. F., Waltner-Toews, D., Schuster, C., Maarouf, A. R., Holt, J. D. (2006): A role of high impact weather events in waterborne disease outbreaks in Canada, 1975 - 2001. - International Journal of Environmental Health Research 16(3): 167-180.

[39] Wellington Dufferin Guelph Public Health. (2016): Moving Ahead. Wellington-DufferinGuelph Public Health Strategic Plan 2011-2016. - Available at: https://www.wdgpublichealth.ca/about/strategic-plan [Accessed 10 September 2017]

[40] Williams, D. R., Costa, M. V., Odunlami, A. O., Mohammed, S. A. (2008): Moving upstream: How interventions that address the social determinants of health can improve health and reduce disparities. - Journal of Public Health Management and Practice 14 Suppl. (6): 8-17.

[41] Wilson, J., Aramini, J., Clarke, S., Novotny, M., Quist, M., Keegan, V. (2009): Retrospective Surveillance for Drinking Water-Related Illnesses in Canada, 1993-2008. Novometrix Research Inc. http://www.ncceh.ca/sites/default/files/DW_Illnesses_Surveillance_Aug_2009.pdf

[42] Xie, Y., Cole, C. A., Long, D. A. (1999): Training center targets small system operators. - American Water Works Association Journal 91(4): 123. 